\title{
Annual performance enhancement of building integrated photovoltaic modules by applying phase change materials
}

\author{
J. H. C. Hendricks and W. G. J. H. M. van Sark* \\ Science, Technology and Society, Copernicus Institute, Utrecht University, Budapestlaan 6, 3584 CD Utrecht, The Netherlands
}

\begin{abstract}
The performance of photovoltaic (PV) module outdoors suffers from attained high module temperatures due to irradiation as a result of the negative temperature coefficient of their efficiency. Phase change materials (PCMs) are investigated as an option to regulate photovoltaic module temperature and thereby reduce its electrical efficiency decrease. In this study, a simplified heat balance model is used to calculate the extra energy gain; such a PV/PCM system can bring on an annual basis. With present day commercially available PCM materials, a moderate increase of up to $3 \%$ of the total energy output can be expected. When taking into account the additional PCM material cost, a PV/PCM module presently is not economically viable. For an acceptable payback period of 10-20 years to be reached, the heat storage capacity of a PCM would require an increase of about one order of magnitude, which is presently not realistic. Nevertheless, a combination with building climate control in which the PCM plays a double role controlling both the PV temperature as well as the inside climate temperature may be feasible. Copyright (C) 2011 John Wiley \& Sons, Ltd.
\end{abstract}

KEYWORDS

BIPV; PCM; annual performance enhancement

* Correspondence

Wilfried van Sark, Science, Technology and Society, Utrecht University, Copernicus Institute, Budapestlaan 6, 3584 CD, Utrecht, The Netherlands.

E-mail: w.g.j.h.m.vansark@uu.nl

Received 11 November 2010; Revised 2 September 2011; Accepted 28 October 2011

\section{INTRODUCTION}

\subsection{Photovoltaics and temperature}

Typical commercial silicon-based photovoltaic (PV) modules convert only 10-20\% of the incident light into electricity; the rest is either reflected or transformed into heat, which causes a rise in temperature of the PV module [1-3]. Elevated operating temperatures are known to reduce the solar to electrical conversion efficiency by $0.4-0.5 \% \mathrm{~K}^{-1}[4,5]$. These temperature-related efficiency losses are reported to account for $7.6 \%$ of the total conversion loss on a yearly basis, making temperature a significant factor to account for [6]. Consequently, one of the options to enhance efficiency is to keep the temperature of the PV module as low as possible, preferably at the operating level of the so-called standard test conditions (STC) of $25^{\circ} \mathrm{C}$. Especially in building integrated PV (BIPV), where modules are integrated in the building envelope and no natural ventilation on the rear side of the panel is generally possible, the temperature of the modules may rise to temperatures of $60-80^{\circ} \mathrm{C}$, leading to a $25 \%$ loss in power with respect to STC. For PV modules that are attached to a building after construction, the so-called building-added PV [7], temperature effects are less severe. Because of the extra increase in temperature, BIPV is the first candidate to find solutions for temperature reduction. At the moment, BIPV makes up less than 5\% in the current European PV market, but it has great potential because of high year-on-year growth and the increasing number of countries with supportive legislation [8].

There are several techniques known that can limit the temperature rise of BIPV. Heat can be dissipated in a passive way using the natural convection of air in a duct behind the PV module, but this is limited by a low rate of heat removal and accumulation of dust. Other active techniques that can be applied are forced air-cooling, hydraulic cooling, or heat pipes. These might require 
additional energy use as well as construction costs. Recently, Huang and coworkers [9-12] have reported on the use of phase change materials (PCMs) as a possible option to regulate the temperature rise of BIPV. With the use of environmentally friendly PCMs such as Rubitherm RT20 and fins to enhance conductivity, it is possible to reach a $10^{\circ} \mathrm{C}$ temperature reduction for $5 \mathrm{~h}$ at $1000 \mathrm{~W} / \mathrm{m}^{2}$ insolation. These materials are characterized by a large latent heat and thermal conductivity and can absorb large amounts of energy at their phase transition temperature. PCMs can be combined in a PV/PCM system in which the excess heat of the PV panel is absorbed by the PCM, that is, the PCM acts as a latent heat storage reducing the PV module temperature increase during its phase change, and thus increasing its electrical efficiency.

The objective of this paper is to estimate the total gain in energy output. A PV/PCM system set-up could give a yearly basis, with attention for the significance of this energy gain and consequently the cost-effectiveness of such a system. For this estimation to be made, a simple simulation model has been developed to calculate the energy gain using yearly insolation and ambient temperature data and properties of different commercially available PCMs.

\subsection{Phase change materials}

Phase change materials have been investigated over the last 20 years as an efficient latent heat storage material [13-15]. Using phase change materials as latent heat storage makes it possible to store 5-14 times more heat per unit volume than sensible heat storage because of the phase change that occurs [14]. Many applications of PCMs as latent heat storage have been investigated and are summarized in [13-15]. A wide selection of PCMs is known with a heat of fusion in any required range, but a PCM requires several thermodynamic, kinetic, and chemical properties to be applicable in the desired way [14]. In particular, for the application studied here, an appropriate phase-change temperature in combination with a high latent heat of fusion and a good heat transfer/conductivity is required. In addition, the PCM volume should not change during the phase change. Of course, it should preferably be stable ( $>20-30$ years), non-toxic and noncorrosive, cheap, and highly abundant. All PCMs share a common problem of generally low heat conductivity because of the crystallizing and thickening agents that are used to prevent supercooling and phase separation [16]. An overview of positive and negative features for each group is given in [13,14]. Sharma [14] reviews an extensive number of PCM applications, where it is clarified that in most cases, either paraffin waxes or salt hydrates are chosen as the best candidates, for example, commonly used PCMs in building applications are salt hydrates and hydrocarbons.

Kenesarin and Mahkamov [17] describe several companies that are currently producing PCMs for the market. One of these companies is Rubitherm $\mathrm{GmbH}$, which produces PCMs on the basis of paraffins and waxes; these are non-toxic, ecologically harmless, and 100\% recyclable [18] and, therefore chosen as the standard in model runs in this paper (more specific RT-27). Other commercial PCMs that are used in our model runs are Thermusol HD35 fabricated by Capzo International and Micronal DS5001 by BASF. Both these PCMs are encapsulated so they keep their solid structure, which makes them easier to handle.

\section{PHASE CHANGE MATERIAL PHOTOVOLTAIC SYSTEM MODEL}

The model compares the temperature evolution of a reference PV system and a PV/PCM system. The difference in temperature is then used to calculate the extra energy output of the PV module by using an empirical relation. A schematic representation of this idea is shown in Figure 1, on the basis of the data reported by Hasan et al. [9], where the temperature evolution of the PV/PCM systems gradually increases the PV reference temperature due to heat absorption by the PCM. The shaded area represents the thermal regulation enhancement.

\subsection{Energy balance}

Figure 2 shows the energy transfers that occur in the modeled PV/PCM system. This is a combination of the energy transfers for a common PV module system and an extra conduction of heat from the PV into the PCM. The common PV energy transfers are largely based upon the temperature model developed by Jones and Underwood [19] and a BIPV-Thermal model by Anderson et al. [20]. The module temperature is dependent on a range of variables such as module material and weather conditions and the surrounding environment.

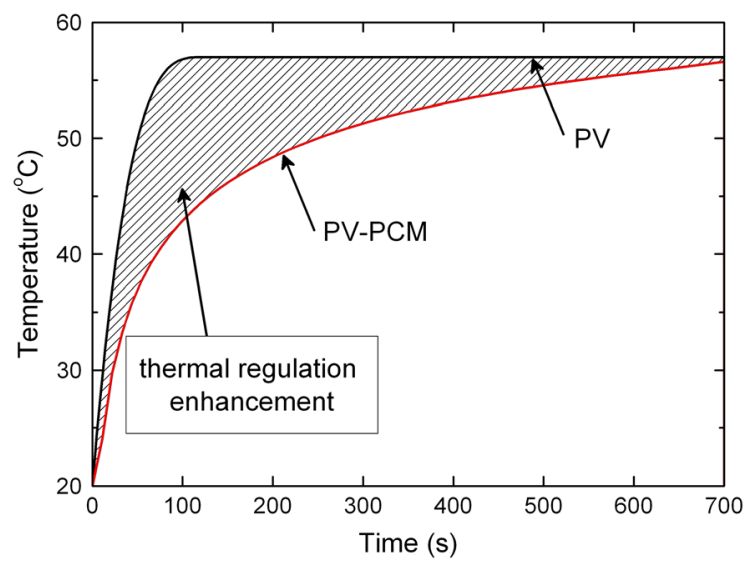

Figure 1. Schematic temperature evolutions for photovoltaic (PV) reference and PV/phase change material (PCM) system, serving as an illustration of a slowed temperature increase, after [9]. 


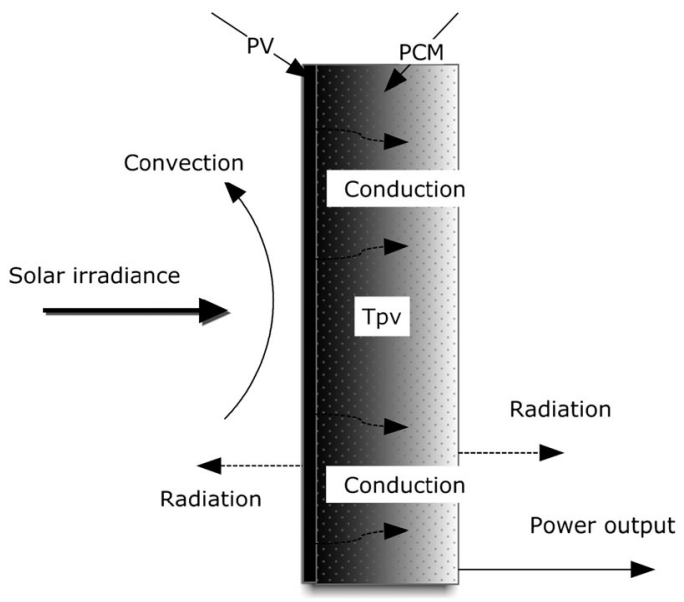

Figure 2. Representation of a photovoltaic/phase change material (PV/PCM) system set-up showing all energy flows used in the model, after [10].

The energy transfers in Figure 2 can be represented in the following heat balance, where the rate of temperature change is expressed as the sum of these:

$$
\frac{d T_{\mathrm{PV}}}{d t}=\frac{q_{\mathrm{s}}-q_{\mathrm{rad}}-q_{\mathrm{conv}}-P_{\mathrm{out}}}{C_{\mathrm{PV}}}-\frac{q_{\mathrm{cond}}}{C_{\mathrm{PCM}}}
$$

where $C_{\mathrm{PV}}$ and $\mathrm{C}_{\mathrm{PCM}}$ are the specific heat capacities of the PV module and PCM, respectively, $q_{\mathrm{s}}$ is the insolation, $q_{\mathrm{rad}}$ is the radiation loss, $q_{\text {conv }}$ is the convective heat loss, $q_{\text {cond }}$ is the conductive heat loss, and $P_{\text {out }}$ is the power generated by the PV module. The last term represents the difference between a reference PV system and a PV/PCM system.

The irradiance accounts for the total input of solar insolation and is defined as

$$
q_{\mathrm{s}}=\alpha \Phi A
$$

where $\Phi$ represents the total solar energy input $\left(\mathrm{W} / \mathrm{m}^{2}\right)$, $\alpha$ is an absorptivity constant, and $A$ is the area of the module $\left(\mathrm{m}^{2}\right)$.

The net radiative heat transfer of the module $q_{\mathrm{rad}}$ is expressed in the following way:

$$
q_{\mathrm{rad}}=2 h_{\mathrm{r}} A\left(T_{\mathrm{PV}}-T_{\mathrm{amb}}\right)
$$

with

$$
h_{\mathrm{r}}=\sigma \varepsilon_{\mathrm{PV}}\left(T_{\mathrm{PV}}^{2}+T_{\mathrm{s}}^{2}\right)\left(T_{\mathrm{PV}}+T_{\mathrm{s}}\right)
$$

Here, $\sigma$ is the Stefan-Boltzmann constant $\left(5.6693 \times 10^{8}\right.$ $\mathrm{W} / \mathrm{m}^{2}$ ), and $\varepsilon_{\mathrm{PV}}$ is the emissivity of the module. $T_{\mathrm{S}}$ is defined as the sky temperature using a modified Swinbank equation [20,21]:

$$
T_{\mathrm{s}}=0.037536 T_{\mathrm{amb}}^{1.5}+0.32 T_{\mathrm{amb}}
$$

with $T_{\text {amb }}$ as the ambient temperature.

The heat loss caused by convection can be defined as

$$
q_{\mathrm{conv}}=A h_{\mathrm{total}}\left(T_{\mathrm{PV}}-T_{\mathrm{amb}}\right)
$$

where the heat loss coefficient $h_{\text {total }}$ is split in a forced component by wind ( $\left.h_{\text {front,forced }}\right)$ and a natural component induced by the temperature difference $\left(h_{\text {front,natural }}\right)$. These are given by [20]

$$
\begin{aligned}
& h_{\text {front,natural }}=1.78\left(T_{\mathrm{PV}}-T_{\mathrm{amb}}\right)^{1 / 3} \\
& h_{\text {front,forced }}=2.8+3.0 \mathrm{v}
\end{aligned}
$$

where $v$ is the wind speed. The separate coefficients are combined in the following way to make up the total heat loss coefficient [20]:

$$
h_{\text {total }}=\left(h_{\text {front,natural }}^{3}+h_{\text {front,forced }}^{3}\right)^{1 / 3}
$$

The focus of the present research is on BIPV systems, meaning that the rear side of the solar panel will be mounted in a building, and it is therefore assumed that there will be no convection loss there [22].

For the calculation of the temperature difference between a PV reference system and a PV/PCM system, it is necessary to add a component to the PV/PCM energy balance that accounts especially for the heat storage by the PCM. Modeling thermal flows of a PCM has been investigated thoroughly for the last 15 years but remains a challenging task [23-26]. A three-dimensional PCM thermal control model has been developed by Huang et al. [12] that use computational fluid dynamics to predict the PCM temperature inside a small container, which is dependent on the viscosity of the fluid and the movement of the solid-liquid boundary. Lamberg et al. [16,27,28] have established an analytical and numerical solution for melting in a semi-infinite PCM storage using a heat equation for solid-liquid interface that is based on a one-phase Stefan problem.

In this paper, the problem of heat uptake of the PCM is reduced to a simplified conduction term that describes the amount of energy that is stored by the PCM over time by introducing a heat absorbance factor $S$. The following expressions are used for the conduction part in three temperature-dependent states:

$$
\begin{aligned}
& q_{\text {cond }, 1}=A k x\left(T_{\mathrm{PV}}-T_{\mathrm{amb}}\right) \\
& q_{\text {cond }, 2}=A k x H\left(T_{\mathrm{PV}}-T_{\mathrm{m}}\right) \\
& q_{\text {cond }, 3}=A k x\left(T_{\mathrm{PV}}-T_{\mathrm{amb}}\right)
\end{aligned}
$$

for $T_{\mathrm{amb}}<T_{\mathrm{PV}}<T_{\mathrm{m}}$

for $T_{\mathrm{m}}<T_{\mathrm{PV}}, \sum k H S\left(T_{\mathrm{PV}}-T_{\mathrm{m}}\right) \leq H m$

for $T_{\mathrm{m}} \geq T_{\mathrm{PV}}, \sum k H S\left(T_{\mathrm{PV}}-T_{\mathrm{m}}\right) \geq H m$ 
in which $k$ is the heat conductivity, $x$ is the PCM thickness, $H$ is the latent heat, and $m$ is the total mass of the PCM material. The temperature difference between the front and the rear side of the system is chosen as the difference between ambient and module temperature when the PCM is not yet acting as heat storage. When the melting temperature is reached, this difference is between melting and system temperature and the latent heat is included. When the temperature is above the melting temperature, the heat stored in the PCM is summed over the total of time steps and is verified if the summation has reached the total heat storage capacity of $\mathrm{Hm}$.

When modeling the phase change, this latent heat $H$ must ideally be modeled as a continuous and invertible function of temperature $(h(T))$ because there is a phase change region [29]. This mathematical approach is beyond the scope of this paper and will increase the already long calculation times $\left(5 \times 10^{6}\right.$ time steps for yearly runs). Therefore, the latent heat is constant in the equation and not temperature dependent. Instead, an extra parameter $S$, denoted as heat absorbance factor, is added to the boundary condition that accounts for a simple diffusion of the heat uptake for every time step. The value for the heat absorbance factor $S$ is based upon the experimental results of Huang and Hasan et al. [9-11].

The final term in the energy balance is the power output of the module. This is an energy output dependent on the insolation $C_{\mathrm{FF}}$ and temperature of the module and described as follows [19]:

$$
P_{\mathrm{out}}=C_{\mathrm{FF}} \frac{\Phi \ln \left(k_{1} \cdot \Phi\right)}{T_{\mathrm{PV}}}
$$

in which $C_{\mathrm{FF}}$ is a fill factor model constant $\left(1.22 \mathrm{~K} \mathrm{~m}^{2}\right)$ as well as $k_{1}\left(10^{6} \mathrm{~m}^{2} \mathrm{~W}^{-1}\right)$.

The total expression for temperature change of the PV/PCM system now becomes

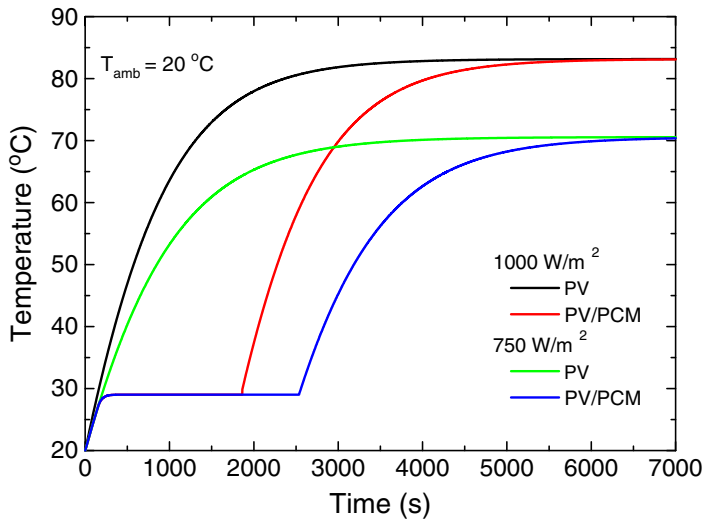

Figure 3. Example of temperature evolutions for both photovoltaic (PV) reference and PV/phase change material (PCM) system, under different constant irradiation $\left(750\right.$ and $\left.1000 \mathrm{~W} / \mathrm{m}^{2}\right)$; ambient temperature $T_{\mathrm{amb}}=20^{\circ} \mathrm{C}$. Three stages can be distinguished for the PV/PCM case; first, the module temperature increases up to the melting temperature of the PCM (here, $300 \mathrm{~K}$, for RT-27) after about $200 \mathrm{~s}$. When the melting temperature is reached, the conduction term including the latent heat is activated (second stage) and keeps the temperature on a steady level until the total heat storage of the PCM is reached (1800 and 2500 s for 750 and $1000 \mathrm{~W} / \mathrm{m}^{2}$, respectively).

[24] and Vyshak [30] of temperature evolutions of the middle of a PCM container both show a similar threestep behavior as in our model, which supports the simplified approach used.

\subsection{Energy output enhancement and payback period}

The simulated temperature difference between the reference system and the PV/PCM is used to calculate the difference in energy output at every time step. This is

$$
\frac{d T_{\mathrm{PV}}}{d t}=\frac{A \cdot \Phi \cdot \alpha+A \cdot 2 \sigma \cdot \varepsilon_{\mathrm{PV}}\left(T_{\mathrm{PV}}^{2}+T_{\mathrm{s}}^{2}\right)\left(T_{\mathrm{PV}}+T_{\mathrm{s}}\right)\left(T_{\mathrm{PV}}-T_{\mathrm{amb}}\right)-C_{\mathrm{FF}} \cdot \frac{\Phi \ln (k 1 \cdot \Phi)}{T_{\mathrm{PV}}}-h_{\mathrm{total}} \cdot\left(\mathrm{T}_{\mathrm{PV}}-T_{\mathrm{amb}}\right)}{C_{\mathrm{PV}}}-\frac{q_{\mathrm{cond}}}{C_{\mathrm{PCM}}}
$$

The Euler method is taken as numerical method to calculate $T_{\mathrm{PV}}$ for every time step. Figure 3 shows the temperature evolutions when using these expressions for two different insolation values, that is, 750 and $1000 \mathrm{~W} / \mathrm{m}^{2}$ (model data as shown in Table I) Clearly, three stages can be distinguished for the PV/PCM case: first, the module temperature increases up to the melting temperature of the PCM (here $300 \mathrm{~K}$ ) after about $200 \mathrm{~s}$. When the melting temperature is reached, the conduction term including the latent heat is activated (second stage) and keeps the temperature on a steady level until the total heat storage of the PCM is reached (1800 and $2500 \mathrm{~s}$ in Figure 3), after which, the temperature resumes its normal rising curve in stage three. Results from Wang carried out with an empirical relation that uses a given percentage of power decrease per degree Kelvin $(d)$. This percentage is experimentally set at $d=0.65 \%$ for a silicon type cell $[31,32]$ and can be varied for other types of PV cells.

This results in the following expressions for energy output for each time step $n$ :

$$
\begin{gathered}
E_{\mathrm{ref}, n}=A \eta \alpha \Phi_{n} \Delta t \\
E_{\mathrm{PCM}, n}=E_{\mathrm{ref}, n}\left[1+d\left(T_{\mathrm{ref}, n}-T_{\mathrm{PV}, n}\right)\right]
\end{gathered}
$$

where $E_{\text {ref }}$ signifies the reference energy output, which is the starting point for the increase in energy output due to 
Table I. Standard parameters used in model runs.

\begin{tabular}{|c|c|c|}
\hline Parameter & Symbol & Values \\
\hline \multicolumn{3}{|l|}{ Photovoltaic (PV) panel } \\
\hline Panel area $\left(\mathrm{m}^{-2}\right)$ & $A$ & 1 \\
\hline Absorptivity constant ${ }^{1}$ & $\alpha$ & 0.95 \\
\hline Efficiency & $\eta$ & 0.15 \\
\hline Mass PV panel (glass) (kg m${ }^{-2}$ ) & $m$ & 25 \\
\hline $\begin{array}{l}\text { Specific heat PV panel (glass) } \\
\left(\mathrm{J} \mathrm{kg}^{-1} \mathrm{~K}^{-1}\right)\end{array}$ & $C_{\mathrm{PV}}$ & 500 \\
\hline Power decrease $\mathrm{K}^{-1}$ & $d$ & 0.0065 \\
\hline Stefan-Boltzmann constant & $\sigma$ & $5.67 \times 10^{-8}$ \\
\hline Emissivity sky² & $\varepsilon_{\mathrm{S}}$ & 0.95 \\
\hline Emissivity module & $\varepsilon_{\mathrm{PV}}$ & 0.90 \\
\hline Average windspeed Malaga $\left(\mathrm{m} \mathrm{s}^{-2}\right)$ & $u_{m}$ & 2.0 \\
\hline Average windspeed Utrecht $\left(\mathrm{m} \mathrm{s}^{-2}\right)$ & $u_{u}$ & 3.3 \\
\hline Fill factor Constant $\left(\mathrm{K} \mathrm{m}^{2}\right)$ & $C_{\mathrm{FF}}$ & 1.22 \\
\hline \multicolumn{3}{|l|}{$P C M(R T-27)$} \\
\hline Width (m) & $x$ & 0.04 \\
\hline Heat absorbance factor & $S$ & 0.04 \\
\hline Conductivity $\left(\mathrm{W} \mathrm{m}^{-1} \mathrm{~K}^{-1}\right)$ & k & 0.2 \\
\hline Melt temperature $(\mathrm{K})$ & $T_{m}$ & 300 \\
\hline Specific heat $\left(\mathrm{J} \mathrm{kg}^{-1} \mathrm{~K}^{-1}\right)$ & $C_{\mathrm{PCM}}$ & 2000 \\
\hline Latent heat $\left(\mathrm{kJ} \mathrm{kg}^{-1}\right)$ & $H$ & 184 \\
\hline Density $\left(\mathrm{kg} \mathrm{m}^{-3}\right)$ & $\rho$ & 880 \\
\hline \multicolumn{3}{|l|}{ Yearly insolation } \\
\hline Malaga $\left(\mathrm{kWh} / \mathrm{m}^{2} /\right.$ year) & $G_{M}$ & 1671.7 \\
\hline Utrecht $\left(\mathrm{kWh} / \mathrm{m}^{2} /\right.$ year $)$ & $G_{U}$ & 1105.9 \\
\hline \multicolumn{3}{|l|}{ Average annual temperature } \\
\hline Malaga $\left({ }^{\circ} \mathrm{C}\right)$ & $T_{\mathrm{M}}$ & 17.9 \\
\hline Utrecht $\left({ }^{\circ} \mathrm{C}\right)$ & $T_{U}$ & 10.2 \\
\hline
\end{tabular}

${ }^{1}$ Value is taken from [34].

${ }^{2}$ Emissivity values are taken from [19].

the PCM (Equation 12). This relation assumes that the efficiency of the PV cells will increase with temperature decrease using the reference efficiency as a starting point, $d$ being the increase in $\mathrm{JK}^{-1}$ in percentage. The total energy enhancement during a period is calculated as the sum of the energy gains per time step, or

$$
E_{\mathrm{PCM}}=\sum_{n} E_{\mathrm{PCM}, n}
$$

For the cost-effectiveness of a PV/PCM combination, we balance the gained energy efficiency and the cost of the PCM material used. In this case, a simple payback period (PBP) calculation is used, defined as follows:

$$
P B P(\mathrm{yr})=\frac{P_{\mathrm{PCM}} M_{\mathrm{PCM}}}{E_{\mathrm{PCM}} \mathrm{COE}}
$$

with $\mathrm{P}_{\mathrm{PCM}}$ as the price of the $\mathrm{PCM}(€ / \mathrm{kg}), M_{\mathrm{PCM}}$ as the weight $\left(\mathrm{kg} / \mathrm{m}^{2}\right), \mathrm{E}_{\mathrm{PCM}}$ as the energy enhancement $(\mathrm{kWh} /$ $\mathrm{m}^{2} /$ year), and COE as the cost of electricity $(€ / \mathrm{kWh})$.

\subsection{Model assumptions}

The major assumptions in the model are related to the PCM heat storage. The actual yield is strongly related to the heat absorbance factor $S$, which plays a major role in assigning the total heat storage of the PCM. The important drawback of this approach is the partly incorrect response on density and specific heat of the PCM because of the simplified formulation of the heat storage boundary. This is inconvenient but not limiting the results because the heat absorbance factor $S$ combines the effect of these parameters and thus plays the major role in assigning the total storage capacity of the PCM. Another interesting parameter is the heat conductivity $k$ because it plays a role in the speed of the heat uptake by the PCM. In reality, the conductivity of paraffin waxes is low, but it is clear from the results that the temperature remains constant right after the melting temperature has been reached. In reality, this will be a moderate reduction, and a longer time will have passed before the actual heat storage limit is reached. Assuming the total limit is reached during the day, the same amount of total temperature reduction is to be expected. Because of the linear relation between temperature and PV efficiency, the same amount of efficieny enhancement can be expected in reality as in the model. Besides the simplifications mentioned previously, there might be a small negative effect on the performance of the PV module if the PCM releases its heat back to the PV module when temperatures decline at the end of the day. This concerns PCM melting temperatures above operating temperature but is not included in the model because it is likely not significant. There is a sensitivity analysis included in the results section to assess the significance of some assumptions and parameters.

\section{RESULTS AND DISCUSSION}

The PV/PCM model is used to make estimates about the energy output gain that results from the addition of the PCM to the back of the PV module. Insolation and ambient temperature data for the cities Utrecht (the Netherlands) and Malaga (Spain) are taken from the NASA Surface meteorology and Solar Energy database for the year 1998 [33]. These two cities were chosen to reflect the different behavior of a PV/PCM system in a moderate (Utrecht) and a hot climate (Malaga). The data is given hourly; it was interpolated into smaller time steps of $10 \mathrm{~s}$ for day model runs and $60 \mathrm{~s}$ for yearly runs. Table I contains the parameters for both PV panel and PCM properties that are used in the standard model runs. The calculations are performed using MathWorks MATLAB 2009a (The MathWorks, Inc, Natick, MA, USA). All results are calculated for an area of $1 \mathrm{~m}^{2}$ panel.

\subsection{Daily values}

As an example of the energy gain attained by adding the PCM to the PV module, Figure 4 illustrates the amount that can be expected during a daily period in Utrecht on 24 April. The temperature is kept almost constant for $\sim 2-3$-hour period in the morning, after which, the 

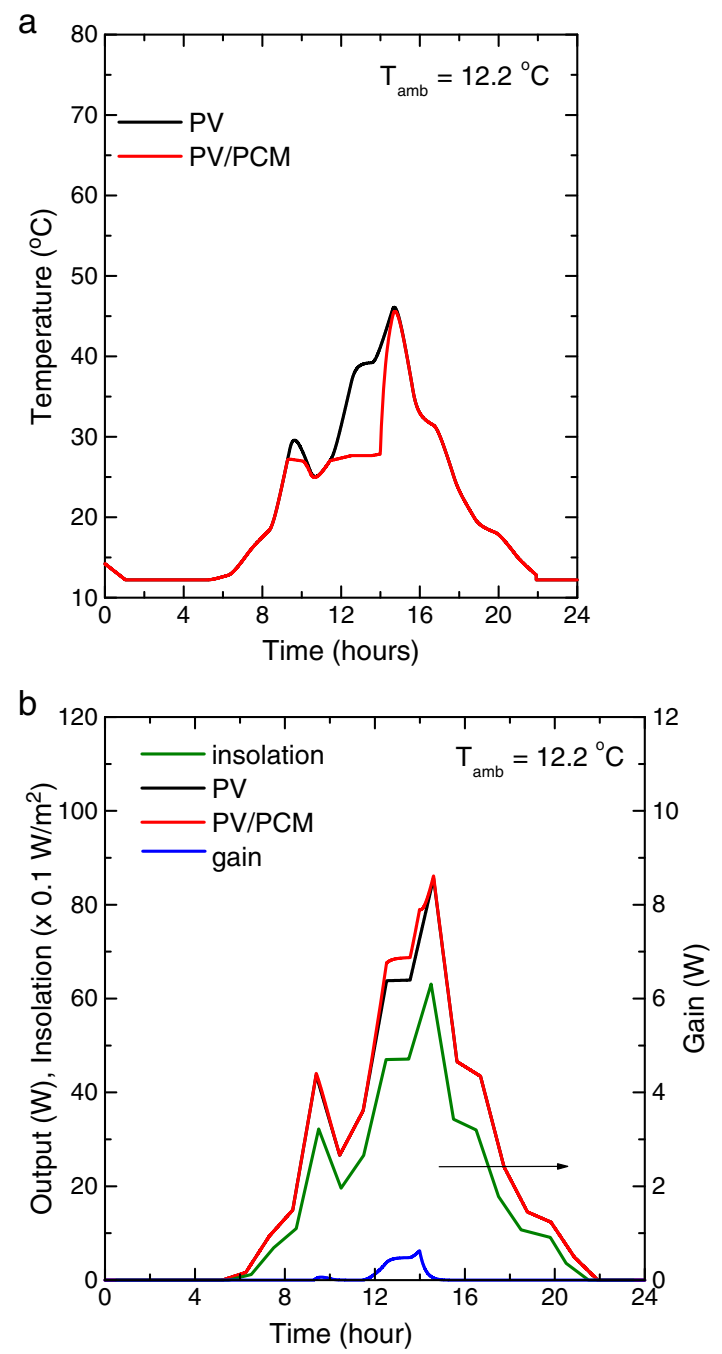

Figure 4. (a) Photovoltaic (PV) reference and PV/phase change material (PCM) temperature evolutions and (b) energy output and insolation for Utrecht on 24 April $\left(T_{a m b}=12.2^{\circ} \mathrm{C}\right)$ with building integrated PV and RT-27 (total energy gain is $3.64 \times 10^{4} \mathrm{~J}$ ). Model data are given in Table I. Note that the right-hand scale (gain) is one order of magnitude lower than the left hand scale.

heat storage capacity is reached and the temperature starts to follow the reference model. Figure 5 shows the results for the same day in Malaga. As the temperature is higher, the duration of constant temperature is also shorter $(2 \mathrm{~h})$ than in Utrecht. At this particular day, the energy gains are about equal.

We have calculated the energy gain for all days in the year. The daily variation of calculated energy gain for Malaga and Utrecht is shown in Figure 6. Interestingly, the energy gain is similar for both cities in the summer season. With this particular PCM mainly in winter, the PV/PCM system in Malaga shows a higher gain than the one in Utrecht. The annual energy gain for Malaga is calculated to be $11.9 \mathrm{MJ}$ (or $3.3 \mathrm{kWh}$ ), whereas the PV reference generates $227 \mathrm{kWh}$ annually. The relative energy
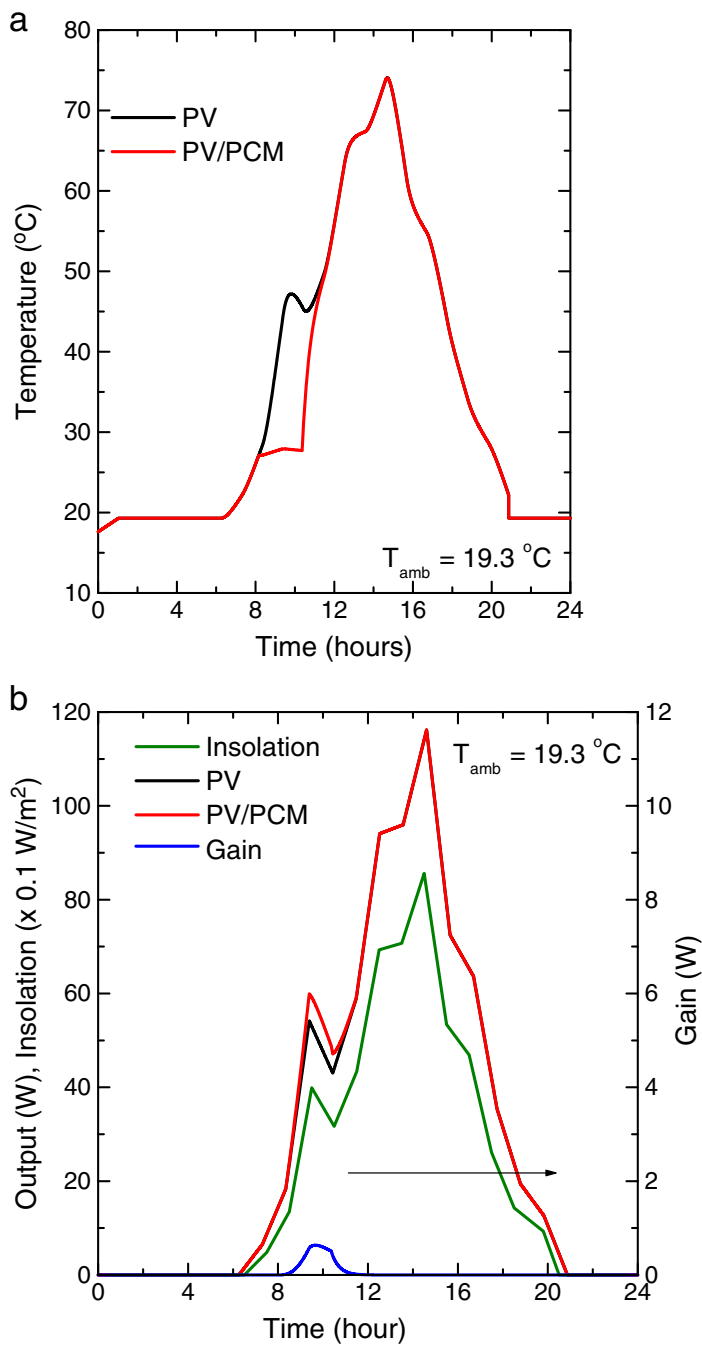

Figure 5. (a) Photovoltaic (PV) reference and PV/phase change material (PCM) temperature evolution and (b) energy output and insolation for Malaga on 24 April $\left(T_{a m b}=19.3^{\circ} \mathrm{C}\right)$ with building integrated PV and RT-27 (total energy gain is $3.37 \times 10^{4} \mathrm{~J}$ ). Note that the right-hand scale (gain) is one order of magnitude lower than the left hand scale.

gain is a modest $1.5 \%$ for this PCM material. In the case of Utrecht, the annual energy gain is $6.3 \mathrm{MJ}$ (or $1.8 \mathrm{kWh}$ ), whereas the PV reference generates $150 \mathrm{kWh}$ annually. The relative energy gain is $1.2 \%$.

A scatter plot is given in Figure 7, which combines daily energy gain and insolation values for a yearly period and shows that Malaga on average has a higher energy gain per day, which is mainly due to its higher insolation values. It is also clear that Utrecht has a lower energy gain at some points while the average insolation values are the same. This can be ascribed to the difference in temperature evolution and insolation during the day because the energy gain is not only dependent on the temperature difference, but also on the value of insolation at a given moment. 

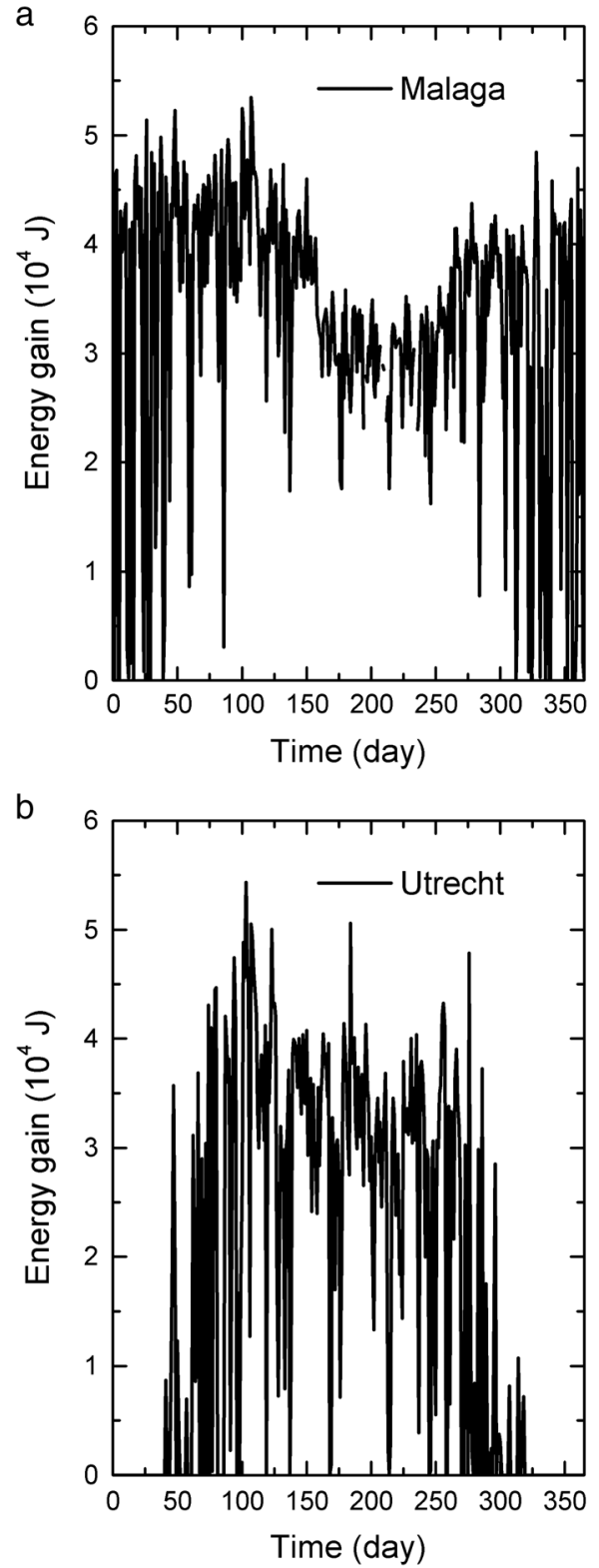

Figure 6. Daily average energy gain $\left(10^{4} \mathrm{~J}\right)$ for Malaga (left) and Utrecht (right), respectively.

\subsection{Sensitivity analysis}

In this section, an analysis is shown on the influence of variations in the important model parameters on the annual energy gain, that is, the PCM melting temperature, the latent heat, the thickness of the PCM, and the heat absorbed factor $S$. The importance of the latter factor is illustrated in Figure 8 , where a maximum latent heat storage is achieved with a value of 0.0004 for the heat absorbed factor $S$, that is, a factor of 100 lower than listed in Table I. Clearly, the PV/PCM module remains at the melting temperature of the PCM, and the resulting energy gain is $0.38 \mathrm{MJ}$; this is $\sim 11$ times larger than the value shown in Figure 5.

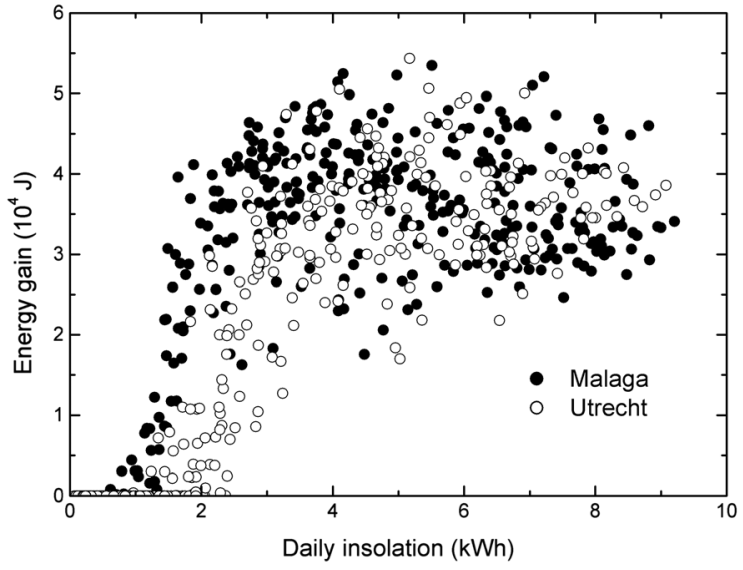

Figure 7. Daily average energy gain $\left(10^{4} \mathrm{~J}\right)$ as a function of daily average insolation for both Malaga and Utrecht.

The annual energy gain results are given in Table II, in $\mathrm{J}, \mathrm{kWh}$, and relative to the annual energy for the reference PV module of 227 and $150 \mathrm{kWh}$ for Malaga and Utrecht, respectively. The annual gain in Utrecht is lower, which is expected because the average insolation and temperature are lower than in Malaga due to weather conditions and latitude. A percentage of the total energy output is included to give a better comparison.

It is clear from the energy gain that Malaga has a better potential for a PV/PCM system, which is mainly due to the weather conditions. From a relative point of view, the standard run shows that a gain of $1.5 \%$ can be expected. With respect to the reference PV module, there is a significant increase using a higher melting temperature $\left(42^{\circ} \mathrm{C}\right)$ in Malaga. Considerable variation of about $+50 \%$ and $-50 \%$ in the latent heat or thickness of the PCM leads to an energy gain in the range of 1-3\% only. The effect of thickness variation is illustrated in Figure 9. The largest variation can be seen when the parameter $S$ is varied: the lower its value, the higher the energy gain, as clearly demonstrated in Figure 10 (and Figure 8). Besides the variation of PCM characteristics shown in Table II, the PV efficiency and wind speed have also been varied. Logically, a $10 \%$ relative increase in PV efficiency leads to a $10 \%$ increase in energy gain. A $10 \%$ lower wind speed leads to a higher gain of $3.5 \mathrm{kWh}$, or $\sim 5 \%$ larger.

\subsection{Commercial phase change materials and cost analysis}

The Rubitherm RT-27 PCM properties are used in all of the standard model runs. Table III shows other commercially available PCMs of which properties have been included in other model runs. These are all paraffin waxes and share properties in the same range. The difference in energy gain is mainly caused by the melting temperature differences. The theoretical maximum represents an ideal situation in which the PCM has unlimited heat storage 
a

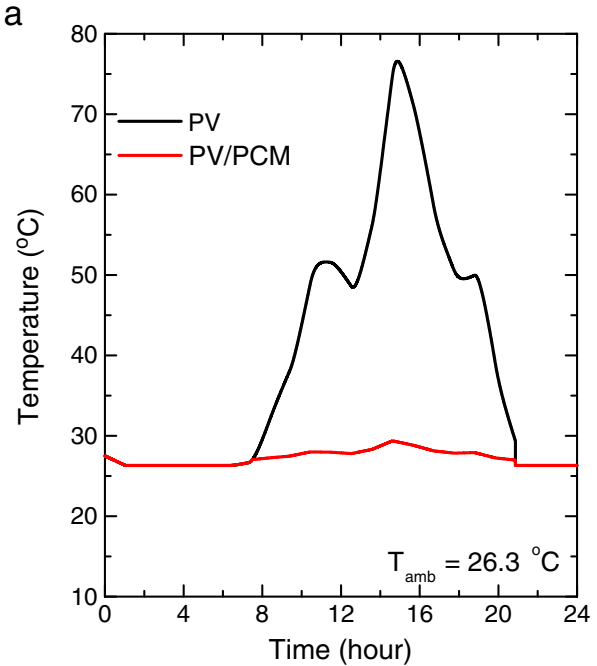

b

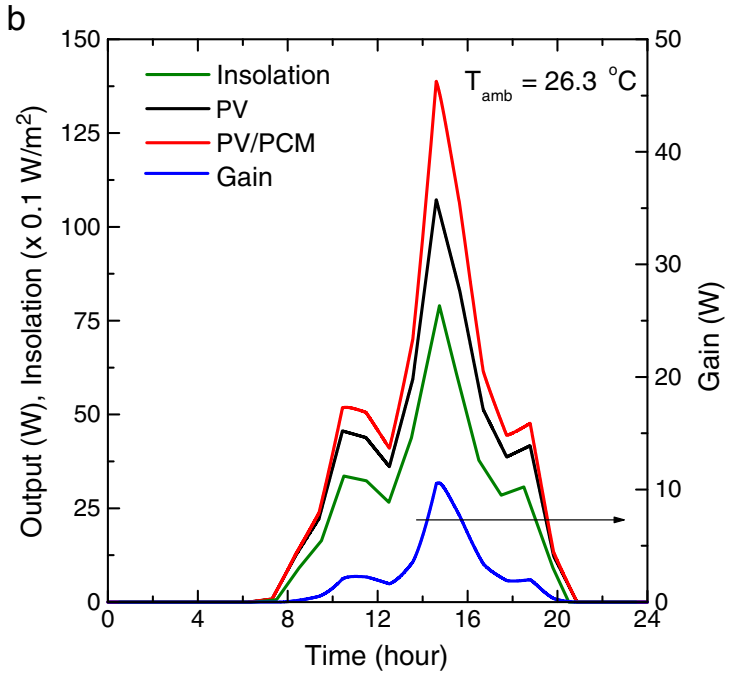

Figure 8. (a) Photovoltaic (PV) reference and PV/phase change material (PCM) temperature evolution (b) energy output and insolation for Malaga for Malaga on 24 August $\left(T_{\mathrm{amb}}=26.3^{\circ} \mathrm{C}\right)$ with maximum latent heat storage using $S=0.0004$ (total energy gain is $3.82 \times 10^{5} \mathrm{~J}$, that is, 11 times larger than Figure 5).

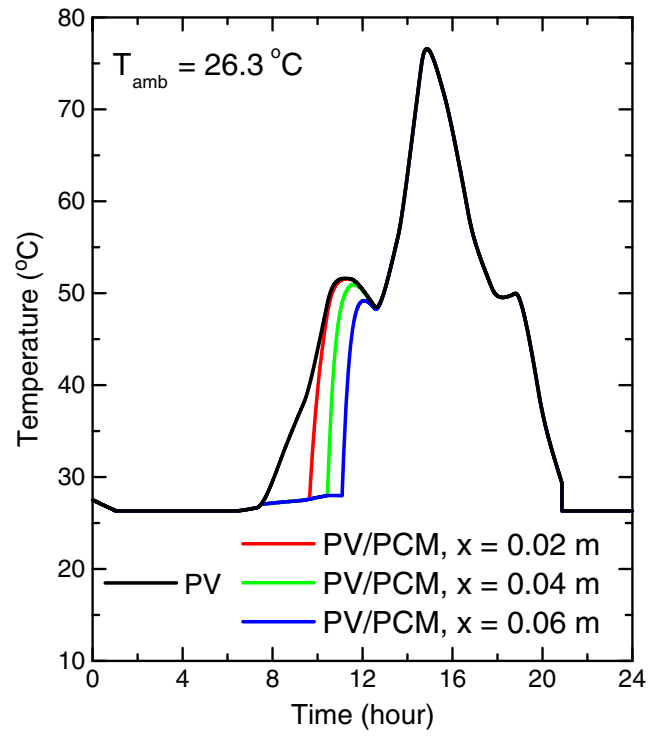

Figure 9. Temperature evolution for the PV/PCM combination with different PCM thicknesses $(x=0.02,0.04,0.06 \mathrm{~m})$ compared to the PV reference; insolation data for Malaga on 24 August (Figure $5(\mathrm{~b})$ ) and $T_{\mathrm{amb}}=26.3^{\circ} \mathrm{C}$.

capacity, that is, the capability of keeping the temperature around operating temperature all day.

The PCM bulk material has to be encapsulated and attached in some form to the back of the PV panel. Additionally, there might be fins needed to enhance the conductivity. These additions are assumed to double the price of the bulk material. The results on energy gain and payback period are shown in Table IV. These show that even with only the bulk material cost taken into consideration, the energy gain of the PV/PCM system does not compare to the cost that is paid for the material. The pay back periods are far beyond an acceptable limit of 20 years. Only when the temperature is kept around STC conditions all year (denoted as theoretical maximum in Table III) the payback period is acceptable.

Table II. Energy gain for different phase change material (PCM) characteristics

\begin{tabular}{|c|c|c|c|c|c|c|c|c|c|c|c|}
\hline \multirow[b]{2}{*}{ Range } & \multicolumn{2}{|c|}{ Melting temperature (K) } & \multicolumn{3}{|c|}{ Latent heat $\left(\mathrm{kJ} \mathrm{kg}^{-1}\right)$} & \multicolumn{3}{|c|}{ PCM width (m) } & \multicolumn{3}{|c|}{$S(-)$} \\
\hline & 300 & 315 & 100 & 184 & 268 & 0.02 & 0.04 & 0.06 & 0.02 & 0.04 & 0.06 \\
\hline Malaga & & & & & & & & & & & \\
\hline$\left(10^{6} \mathrm{~J}\right)$ & 11.9 & 14.6 & 6.4 & 11.9 & 18.0 & 5.3 & 11.9 & 19.2 & 26.9 & 11.9 & 7.4 \\
\hline (kWh) & 3.3 & 4.1 & 1.8 & 3.3 & 5.0 & 1.5 & 3.3 & 5.3 & 7.5 & 3.3 & 2.1 \\
\hline$(\%)$ & 1.5 & 1.8 & 0.8 & 1.5 & 2.2 & 0.6 & 1.5 & 2.3 & 3.3 & 1.5 & 0.9 \\
\hline \multicolumn{12}{|l|}{ Utrecht } \\
\hline$\left(10^{6} \mathrm{~J}\right)$ & 6.3 & 5.2 & 3.7 & 6.3 & 8.9 & 3.1 & 6.3 & 9.6 & 12.8 & 6.3 & 4.1 \\
\hline (kWh) & 1.8 & 1.4 & 1.0 & 1.8 & 2.5 & 0.9 & 1.8 & 2.7 & 3.6 & 1.8 & 1.1 \\
\hline (\%) & 1.2 & 1.0 & 0.7 & 1.2 & 1.6 & 0.6 & 1.2 & 1.8 & 2.4 & 1.2 & 0.8 \\
\hline
\end{tabular}

Percentage calculated on a total of 227 and $150 \mathrm{kWh}$ for Malaga and Utrecht, respectively. The standard run uses a PCM melting temperature of $300 \mathrm{~K}$ (RT27), a latent heat of $184 \mathrm{~kJ} / \mathrm{kg}$, a PCM width of $0.04 \mathrm{~m}$, and a heat absorbance factor of 0.04 . 


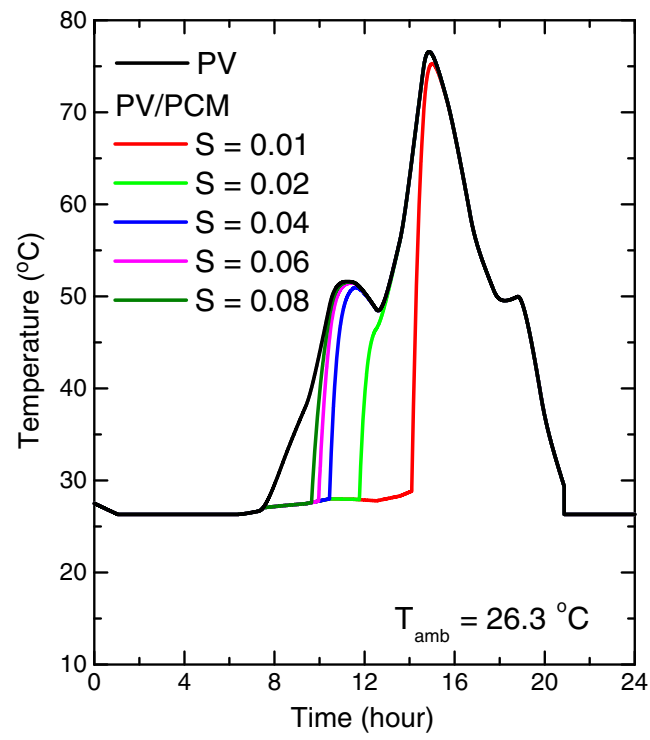

Figure 10. Temperature evolution for the PV/PCM) combination with different values for the heat absorbance factor $S$ compared to the PV reference; insolation data for Malaga on 24 August (Figure $5(\mathrm{~b})$ ) and $T_{\mathrm{amb}}=26.3^{\circ} \mathrm{C}$. Clearly, there is no linear relation between $\mathrm{S}$ and the total capacity of heat storage.

\section{CONCLUSION}

Phase change materials have been investigated as a possible option to limit operating temperature in photovoltaic systems and increase efficiency. Compared with other options of temperature regulation such as forced air circulation design, a PV/PCM combination brings some positive features such as high heat absorption rate, no moving parts, no electricity consumption, and no maintenance cost. Together with the environmentally benign properties of, for example, Rubitherm PCMs, this is a promising approach for temperature reduction.

With the use of properties of these paraffins, a simplified heat balance has been used to model the energy output for a yearly period of insolation for both Utrecht and Malaga. The temperature can be kept constant at the melting temperature for $2-3 \mathrm{~h}$ a day, and this is translated into an energy gain because of the temperature difference and its corresponding increase in PV efficiency. The uncertainty in the model calculations is significant (e.g., weather conditions, reference efficiency, PCM width, etc.), as well as the assumptions made in the simplified conduction model. Sensitivity analysis, however, shows that on average, the yield increase per year of a PV/PCM system is only a $1-3 \%$ of the yield of the PV reference case. However, a theoretical scenario in which the heat storage capacity has no limit, the energy gain is $162 \mathrm{kWh}$, or $71.4 \%$, showing the enormous potential in controlling the operating temperature. The aim of the research was to calculate this yearly yield and also to test its economic viability and assess the possibility of using PCMs as option in the BIPV market. When taking into account the cost of electricity and PCM, it turns out that the extra energy output is too small and the payback period is far beyond an acceptable 20 years limit. This means that the option of PCM as temperature regulation material of $\mathrm{PV}$ in

Table III. Different commercial phase change material (PCM) properties used in model runs.

\begin{tabular}{|c|c|c|c|c|}
\hline Property ${ }^{1}$ & Rubitherm RT-27 & Rubitherm RT-42 & BASF micronal DS 5001 & Thermusol HD35 \\
\hline Melting temperature $\left({ }^{\circ} \mathrm{C}\right)$ & 27 & 42 & 26 & 35 \\
\hline Density $\left(\mathrm{kg} \mathrm{m}^{-3}\right)$ & 880 & 880 & 300 & 780 \\
\hline Heat conductivity $\left(\mathrm{W} \mathrm{m}^{-1} \mathrm{~K}^{-1}\right)$ & 0.2 & 0.2 & n.a.(0.2) & 0.2 \\
\hline Latent heat of fusion $\left(\mathrm{kJ} \mathrm{kg}^{-1}\right)$ & 184 & 174 & 110 & 160 \\
\hline Specific heat capacity $\left(\mathrm{J} \mathrm{kg}^{-1} \mathrm{~K}^{-1}\right)$ & 2000 & 2000 & n.a.(2000) & 2500 \\
\hline
\end{tabular}

Some data were not available (n.a.); data between brackets have been used.

${ }^{1}$ Taken from $[18,35,36]$.

Table IV. Estimates on cost and payback period of several commercially available phase change materials (PCMs) for $0.04 \mathrm{~m}^{3} \mathrm{PCM}$ material.

\begin{tabular}{|c|c|c|c|c|c|}
\hline & \multirow[t]{2}{*}{ Cost $(€ / k g)$ bulk $^{1}$} & \multicolumn{2}{|c|}{ Energy gain ( $\mathrm{kWh} \mathrm{yr}^{-1} \mathrm{~m}^{-2}$ ) } & \multicolumn{2}{|c|}{ Payback period (yr) } \\
\hline & & Malaga & Utrecht & Malaga & Utrecht \\
\hline Rubitherm RT-27 & $2.9-3.5$ & 3.3 & 1.8 & 195-236 & $306-370$ \\
\hline Rubitherm RT-42 & $2.9-3.5$ & 3.9 & 1.4 & 165-199 & $394-475$ \\
\hline Thermusol HD 35 & n.a. (2.5) & 2.7 & 1.3 & 182 & 324 \\
\hline BASF micronal DS5001 & 2.9 & 0.8 & 0.5 & 275 & 376 \\
\hline Theoretical maximum & 2.9 & 162.0 & 43.4 & 4 & 13 \\
\hline
\end{tabular}

PCM properties as given in Table III.Electricity prices used are $0.158(€ / \mathrm{kWh})^{2}$ and $0.185(€ / \mathrm{kWh})$ for Spain and the Netherlands, respectively. Some data were not available (n.a.); data between brackets have been used.

${ }^{1}$ Cost prices are deducted from sources $[17,37,38]$.

${ }^{2}$ Electricity prices from [39]. 
general makes no significant impact on the total energy output of a PV panel, on the basis of the present day materials. Only the theoretical scenario returns an acceptable payback period of 4 years in the case of Malaga; however, PCM materials with a limitless heat storage capacity are not likely to be developed.

An interesting option for PCMs in building integrated PV might be a combination with the inside climate control of the building. There are several methods on the market that use PCMs to keep a controlled inside climate with less energy use (e.g., PCM filled concrete or PCM wallboards [40]). By having the PCM integrated in the roof, it controls the temperature of the PV module and also contributes to the inside climate control. This double role in thermal management could prove a good option for the future, especially because other options such as forced air circulation or hydraulic cooling also require costs for investment and electricity.

\section{ACKNOWLEDGEMENTS}

We would like to thank an anonymous reviewer for pointing out an important inconsistency in the equations used in our original paper.

\section{REFERENCES}

1. Twidell J, Weir T. Renewable Energy Resources. Taylor \& Francis: New York, 2006.

2. Moller H. Semiconductors for Solar Cells. Artech House: Boston, 1993.

3. Wolf H. Semiconductors. Wiley: New York, 1971.

4. Krauter S, Hanitsch R. Actual optical and thermal performance of PV-modules. Solar Energy Materials and Solar Cells 1996; 41/42: 557-574.

5. Radziemska E, Klugmann E. Thermally affected parameters of the current-voltage characteristics of silicon photocell. Energy Conversion and Management 2002; 43: 1889-1900.

6. Iliceto A, Vigotti R. The largest PV installation in Europe: perspectives of multimegawatt PV. Renewable Energy 1998; 15: 48-53.

7. Mei L, Infield D, Gottschalg R, Loveday D, Davies D, Berry M. Equilibrium thermal characteristics of a building integrated photovoltaic roof. Solar Energy 2009; 83: 1893-1901.

8. Sivanandan A. BIPV hotspots in the EU. Renewable Energy Focus 2009; 10(2): 54-55.

9. Hasan A, McCormack S, Huang M, Norton B. Evaluation of phase change materials for thermal regulation enhancement of building integrated photovoltaics. Solar Energy 2010; 84: 1601-1612
10. Huang M. Thermal regulation of building-integrated photovoltaics using phase change materials. International Journal of Heat and Mass Transfer 2004; 47: 2715-2733.

11. Huang M. Phase change materials for limiting temperature rise in building integrated photovoltaics. Solar Energy 2006; 80: 1121-1130.

12. Huang M, Eames P, Norton B. Comparison of a smallscale 3D PCM thermal control model with a validated 2D PCM thermal control model. Solar Energy Materials \& Solar Cells 2006; 90: 1961-1972.

13. Zalba B, Marın JM, Cabeza LF. Review on thermal energy storage with phase change: materials, heat transfer analysis and applications. Applied Thermal Engineering 2003; 23: 251-283.

14. Sharma A, Tyagi V, Chen C, Buddhi D. Review on thermal energy storage with phase change materials and applications. Renewable and Sustainable Energy Reviews 2009; 13: 318-345.

15. Farid MM, Khudhair AM, Razack S. A review on phase change energy storage: materials and applications. Energy Conversion and Management 2004; 45: 1597-1615.

16. Lamberg P, Lehtiniemi R, Henell A. Numerical and experimental investigation of melting and freezing processes in phase change material storage. International Journal of Thermal Sciences 2004; 43: 277-287.

17. Kenisarin M, Mahkamov K. Solar energy storage using phase change materials. Renewable and Sustainable Energy Reviews 2007; 11: 1913-1965.

18. Rubitherm Gmb H. 2010. http://www.rubitherm.com/ (accessed May 13, 2011).

19. Jones AD, Underwood CP. A thermal model for photovoltaic systems. Solar Energy 2001; 70: 349-359.

20. Anderson T, Duke M, Morrison G, Carson J. Performance of a building integrated photovoltaic/thermal (BIPVT) solar collector. Solar Energy 2009; 83: 445-455.

21. Eicker U. Solar Technologies for Buildings. John Wiley and Sons: Chichester, 2003.

22. Jimenez M, Madsen H, Bloem J, Dammann B. Estimation of non-linear continuous time models for the heat exchange dynamics of building integrated photovoltaic modules. Energy and Buildings 2008; 40: 157-167.

23. Zukowski M. Mathematical modeling and numerical simulation of a short term thermal energy storage system using phase change material for heating applications. Energy Conversion and Management 2007; 48: 155-165.

24. Wang X, Yap C, Mujumdar AS. A parametric study of phase change material (PCM)-based heat sinks. International Journal of Thermal Sciences 2008; 47: 1055-1068. 
25. Bony J, Citherlet S. Numerical model and experimental validation of heat storage with phase change materials. Energy and Buildings 2007; 39: 1065-1072.

26. Jie J, Hua Y, Wei H, Gang P, Jianping L, Bin J. Modeling of a novel Trombe wall with PV cells. Building and Environment 2007; 42: 1544-1552.

27. Lamberg P, Siren K. Analytical model for melting in a semi-infinite PCM storage with an internal fin. Heat and Mass Transfer 2003; 39: 167-176.

28. Lamberg P, Siren K. Approximate analytical model for solidification in a finite PCM storage with internal fins. Applied Mathematical Modelling 2003; 27: 491-513.

29. Günther E, Hiebler S. Enthalpy of phase change materials as a function of temperature: required accuracy and suitable measurement methods. International Journal of Thermophysics 2009; 30: 1257-1269.

30. Vyshak N, Jilani G. Numerical analysis of latent heat thermal energy storage system. Energy Conversion and Management 2007; 48: 2161-2168.

31. Radziemska E. Thermal performance of Si and GaAs based solar cells and modules: a review. Progress in Energy and Combustion Science 2003; 29: 407-424.

32. Radziemska E. The effect of temperature on the power drop in crystalline solar cells. Renewable Energy 2003; 28: $1-12$.
33. NASA Atmospheric Sciences Data Center (nd). 2010. Surface meteorology and Solar Energy: http://eosweb. larc.nasa.gov/sse. (accessed May 13, 2011).

34. Santbergen R, Zolingen R. The absorption factor of crystalline silicon PV cells: a numerical and experimental study. Solar Energy Materials \& Solar Cells 2008; 92: 432-444.

35. Micronal PCM. BASF Dispersions \& Pigments. http:// www.micronal.de/portal/basf/ien/dt.jsp?setCursor=1_290798 (accessed May 13, 2011).

36. Capzo. http://www.capzo.nl/ (accessed May 13, 2011).

37. Ekström H, Sundborg H. Phase changing materials and its application in large scale storage of cold, 2010. http:// www.fskab.com/Annex17/Workshops/EM6\%20Arvika/ Presentations/Henrik.pdf (accessed May 13, 2011)

38. Bouwman IM. PCM in the built environment. Combining comfort and sustainability, 2010. http://www. deerns.nl/documents/PCM_Deerns_IBouwman_20081113_v2.0_1.pdf (accessed May 13, 2011)

39. European Commission. EU energy and transport in figures, statistical pocketbook 2010, 2010. http:// ec.europa.eu/energy/publications/statistics/doc/2010_ energy_transport_figures.pdf (accessed May 13, 2011)

40. Chen C, Guo H, Liu Y, Yue H, Wang C. A new kind of phase change material (PCM) for energy-storing wallboard. Energy and Buildings 2008; 40: 882-890. 